\title{
Multiresponse Optimization of Wire Electrical Discharge Machining Parameters for Ti-6Al-2Sn-4Zr-2Mo $(\alpha-\beta)$ Alloy Using Taguchi-Grey Relational Approach
}

\author{
A. Perumal $\mathbb{D}^{1}{ }^{1}$ C. Kailasanathan, ${ }^{1}$ Balasubramaniam Stalin $\mathbb{D}^{2}{ }^{2}$ S. Suresh Kumar, ${ }^{3}$ \\ P. R. Rajkumar, ${ }^{1}$ T. Gangadharan, ${ }^{1}$ G. Venkatesan, ${ }^{1}$ N. Nagaprasad $\left(D,{ }^{4}\right.$ V. Dhinakaran, ${ }^{5}$ \\ and Ramaswamy Krishnaraj $\mathbb{D}^{6,7}$ \\ ${ }^{1}$ Department of Mechanical Engineering, Sethu Institute of Technology, Pulloor, Kariapatti 626115, Tamil Nadu, India \\ ${ }^{2}$ Department of Mechanical Engineering, Anna University, Regional Campus Madurai, Madurai 625 019, Tamil Nadu, India \\ ${ }^{3}$ Department of Mechanical Engineering, Kalasalingam Academy of Research and Education, Krishnankoil 626128, \\ Tamil Nadu, India \\ ${ }^{4}$ Department of Mechanical Engineering, ULTRA College of Engineering and Technology, Madurai 625 107, Tamil Nadu, India \\ ${ }^{5}$ Department of Mechanical Engineering, Chennai Institute of Technology, Kundrathur, Chennai 600069, Tamil Nadu, India \\ ${ }^{6}$ Centre for Excellence-Indigenous Knowledge Innovative Technology Transfer and Entrepreneurship, Dambi Dollo University, \\ Dambi Dollo, Ethiopia \\ ${ }^{7}$ Department of Mechanical Engineering, Dambi Dollo University, Dambi Dollo, Ethiopia
}

Correspondence should be addressed to Ramaswamy Krishnaraj; dr.krishnarajdirectorcei@dadu.edu.et

Received 15 October 2021; Revised 13 January 2022; Accepted 24 January 2022; Published 14 February 2022

Academic Editor: Zhiping Luo

Copyright $\odot 2022$ A. Perumal et al. This is an open access article distributed under the Creative Commons Attribution License, which permits unrestricted use, distribution, and reproduction in any medium, provided the original work is properly cited.

\begin{abstract}
The Ti-6Al-2Sn-4Zr-2Mo alloy was machined using the wire electrical discharge machining (WEDM) method in this research. The consequences of input values like pulse on duration, wire tension, and wire feed on metal removal rate (MRR) and surface roughness (SR) have indeed been observed. After conducting 27 experiments using Taguchi's L27 type of research technique, empirical designing and analysis of variance (ANOVA) were performed. For process optimization, the Taguchi technique, which is based on the grey relational analysis approach, is used. The results show that a material removal rate of $0.293 \mathrm{~mm} / \mathrm{min} \mathrm{was}^{3}$ obtained with factors of $10 \mu \mathrm{s}$ pulse on duration, $7 \mathrm{~m} / \mathrm{min}$ of wire feed, and $12 \mathrm{~g}$ of wire tension (the higher the better), and surface roughness of $2.129 \mu \mathrm{m}$ was obtained with factors of $6 \mu \mathrm{s}$ pulse on duration, $3 \mathrm{~m} / \mathrm{min}$ of wire feed, and $8 \mathrm{~g}$ of wire tension (the lower the better). The percentage of errors between results obtained and grey relational analysis (GRA) predicted results varies around $6 \%$. Wire electrical discharge machining with Ti-6242 alloy to optimum conditions resulted in better MRR and surface integrity with good surface finish and integrity as evidenced by a substantial reduction in the crack formation, lumps, and accumulated surfaces.
\end{abstract}

\section{Introduction}

Wire EDM, also known as a wire-cutting method, is a form of electrical discharge machining (EDM) that uses an electrical discharge to erode the material (sparks). During the wire EDM process, electrode wire is coiled at a constant pace in a standing position from one reservoir to another while maintaining the tension between the two reservoirs.
The wire is fed vertical to the front of the workpiece where the wire inside the workpiece is thoroughly controlled using the computer numerical control (CNC) contouring to control the moves of a wire or table. For WEDM, the electrode wire material is typically made of copper, tungsten, or brass [1-3]. Ionized water is used as a dielectric fluid to protect the workpiece and the tool during the WEDM operation. 
It generates and repeats rapid DC signals thousands of times per second. The fluid becomes ionized at a specific voltage, and sparks are created between both winding wires, eroding the compounds from the workpiece material. To flush out bits, deionized water is continuously sprayed on the workpiece material using nozzles. The workpiece material must be an operator since the WEDM system is based on the electrodischarge process [4-6]. WEDM of lowconductivity work parts, such as polymeric crystal ceramics and cermets, has also been proposed in the new research [7].

The WEDM approach is influenced by a number of parameters, including the following essential factors: workpiece material, wire material, medium of dielectric, spark off-time, peak current, spark on-time, wire feed, workpiece thinness, wire tension, or wire distance end to end presented to the workpiece [8]. Because process factors have such a large impact on machining implementation, they should be thoroughly examined for the best results. The hard Ti-6242 alloy was machined utilizing EDM and MRR; tool wear rate (TWR) and SR have been explored objectively in the proposed research to obtain the optimal execution. The experiments were performed using the Taguchi perfectly straight display method. The essential factors identified from the observable analysis of test results were peak current, spark on time, and voltage [8-11]. Optimized process variables for optimum MRR and minimal surface integrity of Inconel 718 and states that process input variables have such a direct influence on those variables [12]. Hence it is mandatory to optimize the process characteristics using a suitable method. Taguchi method is mostly used for experimental design purposes.

It was used to determine the optimal settings of the processing conditions, which helps to enhance the process. Having solved the two corresponding single-objective optimization problems, a GRA method was applied to determine the processing conditions. Taguchi technique was used to introduce multiresponse optimizing for NiTi type memory alloy WEDM parameters. The pulse duration, pulse-off time, wire tension over cutting speed, kerf width, wire feed, and SR were all investigated. The best conventional methods for a good cutting speed, kerf distance, and surface finish are found [13]. The effect of spark on/off time, feed rate, wire voltage, and conductivity pressure on Inconel's material removal rate and SR was investigated while cutting from side to side into the wire EDM $[14,15]$. The Taguchi method was used to perform multivariable optimizing on Ti-6Al-4V to measure the influence of dielectric conductivity, beat width, beat time, and the highest feed charge, and voltage means servo control, wire feed over material removal [16-18]. Also, on WEDM characteristics of Ti-6Al-4V and Inconel-718, the effect of process factors such as unique discharge current, release on time, and servo voltage was explored. It was discovered that the most significant variables influencing the produced energy are the spark on time and servo voltage [19].

The produce of wire EDM procedure variables on the failure existence of Titanium 6246 alloy aerospace material was discovered [20,21]. A connection between elements involved and response such as material removal rate, kerf, and SR using nonlinear regression analysis methods has been established, resulting in significant numerical models. The width of material removed by a machining process is termed as a "kerf". Finally, the inherited calculation is used to advance the WEDM protocol for multiple places [22-24]. Machining using WEDM attributes pulse off time, servo voltage, and spark on time, and wire-speed has implications for surface integrity, geometric precision, and spark gap formation [25-30]. Optimization of wire-EDM control factors of various presentation values such as MRR, surface roughness (SR), and kerf angle has been improved in the machining of Inconel 800 superb alloy with Wire-EDM based on the Grey Taguchi approach [31-38].

The limited research was carried out for the Ti-6242, specifically with varied process variables. It has been exposed that most of the research is conducted with constant profiles on traditional cross section exteriors. There has been virtually no work on varying performance. Tapered workpieces of Ti-6242 with variable shapes were measured in this investigation because of the need for industry. Therefore the effect of the taper angle on the outcomes of the Titanium alloy WEDM was also discussed to deal with the industrialized requirements. Considering the above-mentioned literature, one or two variables such as surface integrity with MRR or any remaining combination are analyzed using the experimental methods; we chose the WEDM factors such as pulse on time, wire feed, and wire tension. The investigations were led by the implementation of the orthogonal Taguchi array strategy with the study of Grey relationships. The SEM analysis was conducted to investigate the description of the machined apparent.

\section{Experimental Work}

2.1. Work Material. The Ti-6242 alpha-beta alloy utilized in this study was acquired from an Indian mart and had specifications and higher penetration property. In this study, Ti-6242 alpha-beta alloy material with particular dimensions of $6 \mathrm{~mm}$ diameter and $150 \mathrm{~mm}$ in length has been used. It was designed to handle slightly elevated procedures up to $5380^{\circ} \mathrm{C}$. It has exceptional strength and corrosion resistance, as well as moral fatigue strength and fabricability. Figure 1 depicts images of the material after machining. Titanium alloys are materials that include $\mathrm{Ti}$ as well as other chemical constituents in varying proportions. Ti-6242 is a type of material with a high alpha content.

The chemical compositions of Ti-6242 alloy, as well as its mechanical and physical properties, are shown in Tables 1 and 2. The major ingredient in this alloy is $\mathrm{Ti}$, with $\mathrm{Al}, \mathrm{Sn}$, and $\mathrm{Zr}$ serving as alloying elements.

2.2. Investigational Arrangement. Trials were carried out at the National Institute of Technology Tiruchirappalli on a portable (Wire Electrical Discharge Machine EXCETEK V650) Sequence Machine using Ti-6242 alpha beta-alloy as a workpiece $(150 \mathrm{~mm}$ length $\times 6 \mathrm{~mm}$ diameter $)$ with deionized water; $0.25 \mathrm{~mm}$ copper wire is used. Table 1 lists the various process parameters employed in the tests, whereas Figure 2 


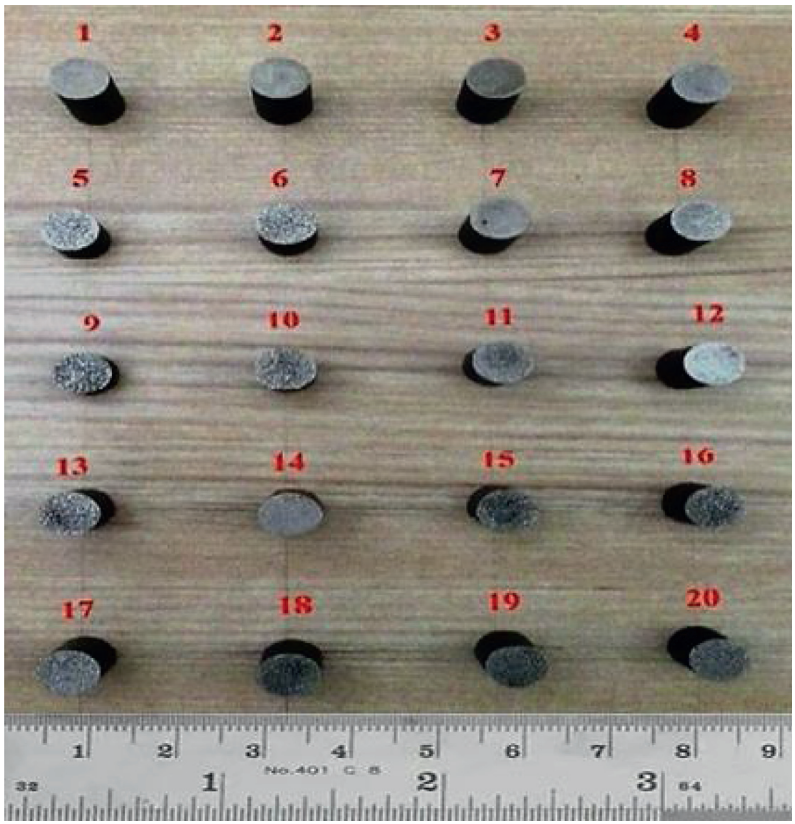

FIGURE 1: Workpieces surface after machining.

TABle 1: The chemical composition of Ti-6242 alpha-beta alloy (in wt.\%).

\begin{tabular}{lccccc}
\hline Titanium & Aluminium & Tin & Zirconium & Molybdenum & Others (H, O, C, N, and Si) \\
\hline $85.0-86.0$ & $5.0-6.0$ & 1.95 & 3.80 & $1.8-2.0$ & $<0.0189$ \\
\hline
\end{tabular}

TABLE 2: Mechanical behaviours of Ti-6Al-2Sn-4Zr-2Mo alloy.

\begin{tabular}{lccccccc}
\hline $\begin{array}{l}\text { Hardness } \\
\text { (rockwell) }\end{array}$ & $\begin{array}{c}\text { Hardness } \\
\text { (Vickers) }\end{array}$ & $\begin{array}{c}\text { Shear } \\
\text { Modulus } \\
(\mathrm{GPa})\end{array}$ & $\begin{array}{c}\text { Ultimate tensile } \\
\text { strength }(\mathrm{MPa})\end{array}$ & $\begin{array}{c}\text { Yield strength } \\
(\mathrm{MPa})\end{array}$ & $\begin{array}{c}\text { Modulus of } \\
\text { elasticity }(\mathrm{GPa})\end{array}$ & $\begin{array}{c}\text { Shear strength } \\
(\mathrm{MPa})\end{array}$ & $\begin{array}{c}\text { Elongation (\%) } \\
\text { at break }\end{array}$ \\
\hline 34 & 332.8 & 46 & 1010 & 899.9 & 120 & 690 \\
\hline
\end{tabular}
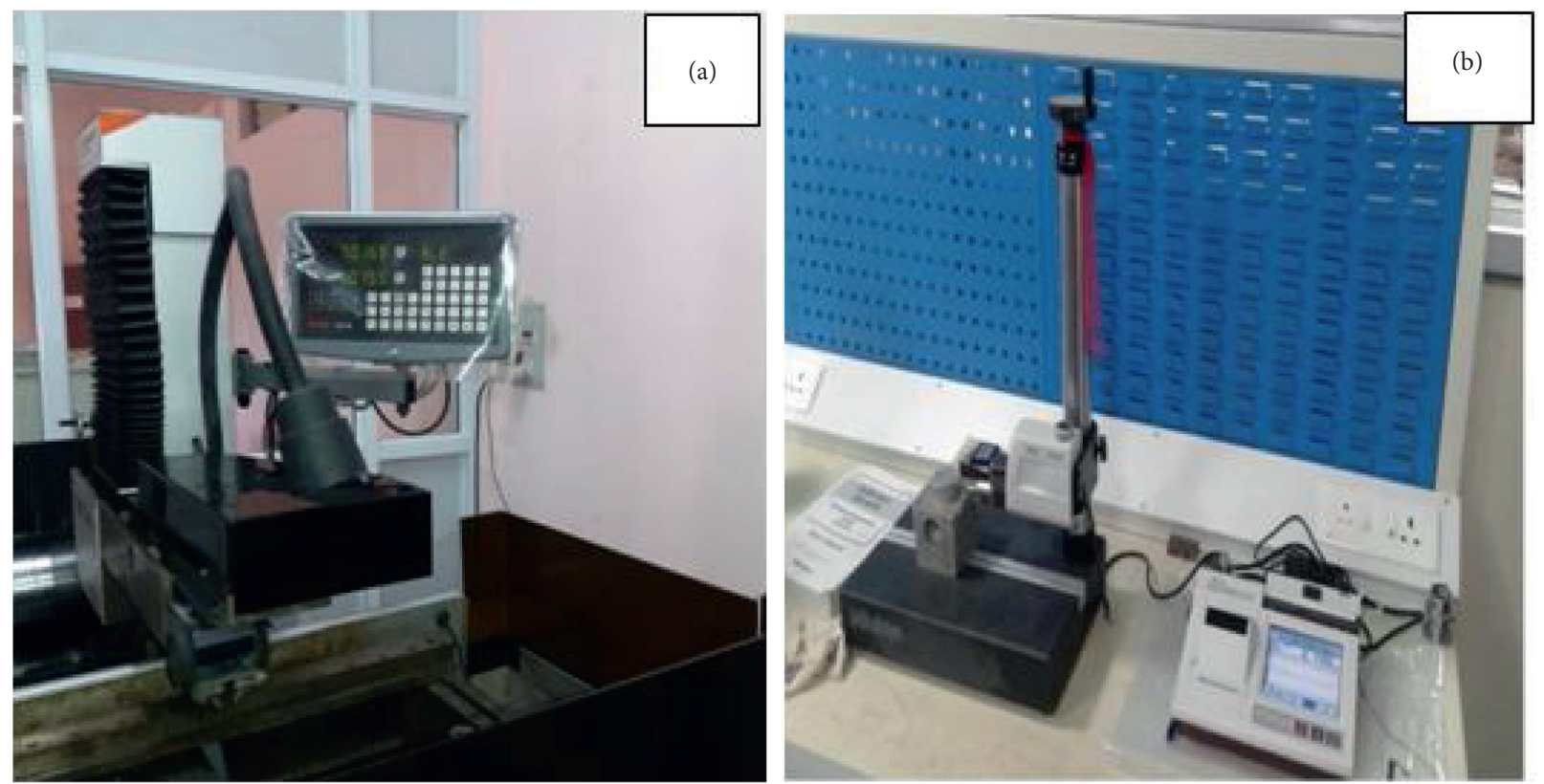

Figure 2: (a) Mitsubishi FX series WEDM setup. (b) Surface roughness setup. 
depicts the experimental setup in detail. Figure 2(a) shows a wire EDM machine, and Figure 2(b) shows a machined surface testing machine where the surface texture specimen is used to calculate the total amount SR.

2.3. Experimental Factors and Design. Component excellence acquired by the WEDM is constantly influenced by the machining parameters practically identical pulse on duration and wire feed, and wire tension reasonable information parameter choice of the machining factors can cause higher MRR and less SR. Taguchi was utilized to decide ideal machining factors for the least SR and greatest MRR in WEDM. The machining input parameters level is presented in Table 3.

In the present investigation, the two process responses are selected to be calculated in the run of the experiment against the control factor settings. These two process responses calculated in the obtainable work are MRR and SR.

The material removal rate is intended by the following:

$$
\text { material removal rate }=\frac{W_{b}-W_{a}}{T_{m} \times \rho}\left(\frac{m^{3}}{\min }\right),
$$

whereas $W_{b}$ is the workpiece weight before machining $(\mathrm{mm}), W_{a}$ is the work piece weight after machining $(\mathrm{mm}), \rho$ is the material density, $\mathrm{kg} / \mathrm{mm}^{3}, T_{m}$ is the machining time (min), surface roughness (SR) $(\mu \mathrm{m})$.

2.4. Surface Roughness Measuring Apparatus. In the examination, the surface roughness (SR) of the WEDM workpiece in terms of regularly utilized surface harshness was estimated by a surface roughness analyzer Mitutoyo surface test 301 testing machine. The average SR is observed for each experiment, and the average of 3 measurements is reported in Table 4.

Taguchi planned to gain the characteristic information by utilizing orthogonal arrays and dissecting the presentation quantity from the information to choose the ideal procedure factors. The structured preparation of information factors and its comparing SR and MRR has appeared in Table 4 particularly.

\section{Results and Discussion}

The planning matrix and the outcome from the tests, primarily material removal rate and surface integrity, are shown in Table 4. After the trial runs, ANOVA was used to inspect the impact of cutting factors of WEDM on the surface integrity and material removal rate.

Taguchi method has been used to get the information by utilizing orthogonal arrays and to break down the presentation measure to the information and choose the ideal procedure parameters. The planned mix of information parameters and its relating MRR and SR has appeared in Table 4 distinctly.

3.1. S/N Ratio Calculation. The ANOVA was utilized to set up factually critical machining constraints and the percent
TABLE 3: Machining causes and their control factor ranks used in the experiments.

\begin{tabular}{lcccc}
\hline Process parameter & Symbols & Level 1 & Level 2 & Level 3 \\
\hline Pulse on duration $(\mu \mathrm{s})$ & $\mathrm{A}$ & 6 & 8 & 10 \\
Wire feed $(\mathrm{m} / \mathrm{min})$ & $\mathrm{B}$ & 3 & 5 & 7 \\
Wire tension $(\mathrm{g})$ & $\mathrm{C}$ & 8 & 10 & 12 \\
\hline
\end{tabular}

association of these variables on output reactions MRR and SR. Presently, by Taguchi technique, less quality work is utilized to figure the difference between the analytical worth and the most appreciated value. This default work is additionally changed into an $\mathrm{S} / \mathrm{N}$ proportion. There are a few realistic signal-noise proportions relying upon kind of qualities: the higher-the-better and the lower-the-better (LB), nominal-the-best. In wire electric release machining activities and lower surface roughness, the higher MRR are vital pointers of better introductions. Subsequently, the misfortune work appearances lower-the-better for SR and higher-the-better for the MRR were chosen for discovering ideal machining execution arrivals.

$$
\begin{gathered}
\eta=-10 \log _{10}\left(\frac{1}{n}\right) \sum_{i=1}^{n} y_{i j}^{2}, \\
\eta=-10 \log _{10}\left(\frac{1}{n}\right) \sum_{i=1}^{n} \frac{1}{y_{i j}^{2}}
\end{gathered}
$$

where $n=$ number of repetitions $y_{i j}=$ experimental reaction value, where $i=1,2, \ldots, n ; j=1,2, \ldots, k$, where (2) is applicable where minimization of the excellent characteristics is intended and (3) for maximization is required [17].

It has been observed from Table 4 that for higher-thebetter, material removal rate of $0.293 \mathrm{~mm}^{3} / \mathrm{min}$ was obtained with the factors of $10 \mu \mathrm{s}$ pulse on duration, $7 \mathrm{~m} / \mathrm{min}$ of wire feed, and $12 \mathrm{~g}$ of wire tension. For lower-the-better, surface roughness $2.129 \mu \mathrm{m}$ was obtained with the factors of $6 \mu \mathrm{s}$ pulse on duration, $3 \mathrm{~m} / \mathrm{min}$ of wire feed, and $8 \mathrm{~g}$ of wire tension.

The following steps are involved in the Taguchi method:

(i) Identifying important WEDM factors and performance factors

(ii) Using trial experimentation to determine the experimental area of a process parameter that affects machining performance and factor levels choosing

(iii) Choosing an orthogonal array (experimental matrix design)

(iv) Experimentation implementation

(v) Taguchi method optimization of control factors

(vi) Calculating the percentage contribution of each process parameter on WEDM using ANOVA

(vii) Confirmation tests used to improve variable levels verification

(viii) Microstructure evaluation of EDM machined surfaces at optimized parameter levels and varied parametric combinations 
TABLe 4: Results of experimental run by Taguchi L27 methods.

\begin{tabular}{|c|c|c|c|c|c|}
\hline \multirow{2}{*}{ S. No. } & \multicolumn{5}{|c|}{ Process parameters } \\
\hline & Pulse on duration $(\mu \mathrm{s})$ & Wire feed $(\mathrm{m} / \mathrm{min})$ & Wire tension $(\mathrm{g})$ & $\operatorname{MRR}\left(\mathrm{mm}^{3} / \mathrm{min}\right)$ & $\mathrm{SR}(\mu \mathrm{m})$ \\
\hline 1. & 6 & 3 & 8 & 0.106 & 2.129 \\
\hline 2. & 6 & 3 & 10 & 0.118 & 2.236 \\
\hline 3. & 6 & 3 & 12 & 0.140 & 2.289 \\
\hline 4. & 6 & 5 & 8 & 0.128 & 2.169 \\
\hline 5. & 6 & 5 & 10 & 0.142 & 2.241 \\
\hline 6. & 6 & 5 & 12 & 0.145 & 2.291 \\
\hline 7. & 6 & 7 & 8 & 0.138 & 2.188 \\
\hline 8. & 6 & 7 & 10 & 0.147 & 2.659 \\
\hline 9. & 6 & 7 & 12 & 0.121 & 2.81 \\
\hline 10. & 8 & 7 & 8 & 0.199 & 3.045 \\
\hline 11. & 8 & 7 & 10 & 0.212 & 3.125 \\
\hline 12. & 8 & 7 & 12 & 0.243 & 3.261 \\
\hline 13. & 8 & 3 & 8 & 0.165 & 2.789 \\
\hline 14. & 8 & 3 & 10 & 0.178 & 2.614 \\
\hline 15. & 8 & 3 & 12 & 0.195 & 2.999 \\
\hline 16. & 8 & 5 & 8 & 0.181 & 2.887 \\
\hline 17. & 8 & 5 & 10 & 0.189 & 2.911 \\
\hline 18. & 8 & 5 & 12 & 0.201 & 3.041 \\
\hline 19. & 10 & 5 & 8 & 0.239 & 2.898 \\
\hline 20. & 10 & 5 & 10 & 0.241 & 2.930 \\
\hline 21. & 10 & 5 & 12 & 0.243 & 3.098 \\
\hline 22. & 10 & 7 & 8 & 0.267 & 3.095 \\
\hline 23. & 10 & 7 & 10 & 0.274 & 3.423 \\
\hline 24. & 10 & 7 & 12 & 0.293 & 3.521 \\
\hline 25. & 10 & 3 & 8 & 0.224 & 2.814 \\
\hline 26. & 10 & 3 & 10 & 0.261 & 3.256 \\
\hline 27. & 10 & 3 & 12 & 0.289 & 3.786 \\
\hline
\end{tabular}

3.2. Grey Relational Analysis (GRA). In control theory, a "White" system is one that is totally known, whereas a "Black" system is one that is totally unknown. The "Grey" system is recognized to be halfway between the "White" and "Black" boundaries, allowing for a model system with limited data collection, low accuracy, and random uncertainty. In the year 1993, Deng pioneered the Grey system theory of ambiguity based on small samples. It is not necessary to use a probabilistic model. The approach for grey relational analysis that was employed in this work to acquire the optimum WEDM parameters as well as to determine the most influential parameters that affect surface roughness and MRR is presented in the following sections. Responses from Ti-6242 alloy specimens are evaluated using ANOVA and the $\mathrm{S} / \mathrm{N}$ ratio. However, the interrelationship specimen is necessary for studying the effect of machining. Grey relational analysis is a statistical approach for resolving interrelationships between various replies. This method yields a grey relational grade for the specimens' structural quality [39]. The optimization of the each sample can be transformed into the optimization of a single grey relational grade. A study work utilizes grey relational analysis to determine the best settings for multiperformance characteristics in machining operations [40].

In GRA, the initial step is to standardize preliminary information achievement from zero to one. The procedure is known as a GRA. Based on controlled investigational information, the count of the GRC, to speak to the connection between the perfect and genuine investigational information, is the subsequent advance. At that point, the last advance is the purpose of grey relational grade (GRG) by and large, which is finished by averaging the Grey relational coefficient (GRC) compared to chosen reactions. The general execution normal for the different reaction forms relies upon the determined GRG. Right now, various response process improvement issues are changed over into a solitary reaction streamlining issue, with the general GRG being the impartial capacity. At that point assessing the ideal parametric mix would result in the most elevated dim social evaluation. In general, to augment dark social evaluation, the ideal component scene can be actualized by the Taguchi strategy.

3.3. Normalization. It is important to control the new values before evaluating them with a relative grey concept [41]. Normalization of responses, namely MRR and SR is calculated by using (4), and it is valued between 0 and 1 .

For lower-the-better,

$$
z_{i j}=\frac{\operatorname{Max}\left(y_{i j}, i=1,2, \ldots n\right)-y_{i j}}{\max \left(y_{i j}, 5 i=1,2, \ldots n\right)-\min \left(y_{i j}, i=1,2, \ldots n\right)},
$$

where $y$ is $j^{\text {th }}$ presentation particular in the experiment, max $y_{i j} \min y_{i j}$ are the large and low value of jet performance characteristic for alternative respectively. 
For higher-the-better,

$$
z_{i j}=\frac{y_{i j}-\min \left(y_{i j}, i=1,2, \ldots n\right)}{\max \left(y_{i j}, i=1,2, \ldots n\right)-\min \left(y_{i j}, i=1,2, \ldots n\right)} .
$$

3.4. Manipulating the Grey Relational Coefficient (GRC) and Grade. Grey relational coefficients from standardized values for output reactions are planned by using the following:

$$
\begin{aligned}
y\left(y_{0}(k), y_{i}(k)\right) & =\frac{\Delta \min +\xi \max }{\Delta_{0 j}(k)+\xi \Delta \max }, \\
\bar{Y} j & =\frac{1}{k} \sum_{i=1}^{m} \gamma_{i j},
\end{aligned}
$$

where $j$ is the GRG for the $j^{\text {th }}$ trial and $k$ is the number of presentation appearances.

GRA is a suitable multiperformance optimization technique to identify the optimum combination of contributing factors and also the novelty of the consequence of respective machining factors on output reactions.

$\mathrm{S} / \mathrm{N}$ ratio was calculated for each reaction and standardization development and also completed for these appearances, which are obtainable between 0 and 1 as displayed in Table 5. GRC was determined for each equivalent value by assuming the grey coefficient standard to be 0.5 . For the variables, the GRG is determined as well. The GRA parameters are presented in Table 5 .

3.5. Response Table. In the Taguchi test, the $\mathrm{S} / \mathrm{N}$ proportion is calculated based on the output response objective using statistical programming in Minitab 17. In the present examination, the MRR is determined as the higher the better, and SR is measured as inferior to the better-quality attributes. The influence of response variables on output responses can be easily identified because of the reaction table and principle impact factors. The table characterizes the reaction table of calculated $S / N$ proportions for $M R R$ and SR. Table 6 depicts the grey relational grade response table, and Table 7 shows the ANOVA for GRG, with adjusted SS for tests.

It has been inferred from the main effects plot for GRG as displayed in Figure 3; there is a moderate association between spark on duration, wire tension, and wire feed in affecting the dimensional deviation. The cooperation of pulse on duration, wire feed, and wire tension is powerless because the collaborations are practically equal. Residual plots are attracted to discover the evidence for the concerns of similar nonordinariness, nonirregular selection, inconsistent change, and greater request connections. The residuals versus fitted qualities demonstrated a kind of inclination for a fluctuation of the residuals to increment as the dimensional deviation esteem increments. The issue, be that as it may, is not sufficiently serious about having any emotional effect on the investigation and ends. It is a typical likelihood plot, histogram plot, and lingering versus perception request plot of these residuals that do not uncover any issue.

The collaboration plot for the GRC is outlined in Figure 4 . Every conceivable association, among the pulse duration, wire tension, and the wire feed, has been planned to generalize the impacts of the elements: how one influence affects the presentation of the alternative issues. The expanding benefit of critical velocity, whenever forced upon the expanding table feed rate, will in general create lower GRG and the other way around. Through the cooperation of pulse duration, wire tension, and the wire feed, the expanded stream rate delivers improved GRG up to the first level, even though the burden of feed and slicing speed will, in general, lessen the impact of flow rate. At that point, at the fourth level, the relational grade is diminished by a huge sum. The first degree of wire feed $(10 \mathrm{~m} / \mathrm{min})$ would, in general, furnish a superior outcome when joined with the other two components.

3.6. Residual Analysis. The ordinary likelihood design of the residuals, remaining verses appropriate, residuals histogram, and lingering against a request for the GRA appears in Figure 5. It is perfect from the typicality plot that the vast majority of the focuses lay sensibly near the straight line, which indicates that the blunders are ordinarily and freely dispersed. The typicality suppositions are viewed as substantial for this bend. Away from a plot of the residuals finished, the fixed qualities are obvious. As a matter of fact, there is no indication of any expanding/diminishing example to invalidate the suspicion of a steady difference. The leftover histogram gives an indication of positive scenes. The greater part of recurrence is extended and finished: -0.030 to +0.045 ; the rest of recurrence is finished at both ends. The residual plot finished perception request displays that there are unexpectedly good and bad times, demonstrating that the residuals are uncorrelated to one another.

Figures 6 and 7 demonstrate the contour plot of the grey relation between pulses on time and wire tension interactions for the surface plot three-dimensional view. Because of the low wire tension and medium pulse on time, the surface plot is small.

3.7. Pulse on Time Effect on the Responses. As paralleled to additional factors such as wire tension and wire feed rate, the spark time has a greater impact on the output responses. As a result, its impact on the MRR oval and SR was investigated and published. Increased pulse length results in a longer electrical spark discharge on the material. As a consequence, craters will form on the machined surfaces, resulting in poor surface integrity. As a result, it has a greater impact on response characteristics with MRR and SR. The getting bombarded forces between the electrode and the material are increased by wire feed, which influences the surface morphology of the titanium alloy. For the difference in the Ti6Al-2Sn-4Zr-2Mo alloy, Figures 8(a) and 8(b) indicate the improvements in the MRR with an improvement in the spark on time. 
TABLE 5: Results of GRA.

\begin{tabular}{|c|c|c|c|c|c|c|c|c|c|}
\hline \multirow[t]{2}{*}{ Experimental trial } & \multicolumn{2}{|c|}{$\mathrm{S} / \mathrm{N}$ ratio } & \multicolumn{2}{|c|}{$\begin{array}{c}\text { Normalized } \mathrm{S} / \mathrm{N} \\
\text { ratio }\end{array}$} & \multicolumn{2}{|c|}{$\begin{array}{l}\text { Deviation } \\
\text { sequence }\end{array}$} & \multicolumn{2}{|c|}{$\begin{array}{l}\text { Grey relational } \\
\text { coefficient }\end{array}$} & \multirow[t]{2}{*}{ Grey relational grade } \\
\hline & MRR & SR & MRR & SR & MRR & SR & MRR & SR & \\
\hline 1 & 10.171 & 19.493 & 0.0023 & 0.6867 & 1.0000 & 0.3133 & 0.2500 & 0.3807 & 0.4994 \\
\hline 2 & 7.92 & 34.89 & 0.6109 & 0.0042 & 0.3891 & 1.0000 & 0.3600 & 0.2500 & 0.4988 \\
\hline 3 & 6.989 & 20.915 & 1.0000 & 0.4542 & 0.0000 & 0.5458 & 0.5000 & 0.3235 & 0.5624 \\
\hline 4 & 8.796 & 14.334 & 0.2797 & 0.7490 & 0.7203 & 0.2510 & 0.2906 & 0.3997 & 0.4977 \\
\hline 5 & 7.857 & 13.433 & 0.7279 & 0.7894 & 0.2721 & 0.2106 & 0.3931 & 0.4130 & 0.5623 \\
\hline 6 & 9.343 & 20.724 & 0.0186 & 0.4628 & 0.9814 & 0.5372 & 0.2523 & 0.3253 & 0.4799 \\
\hline 7 & 7.914 & 24.731 & 0.7007 & 0.2833 & 0.2993 & 0.7167 & 0.3848 & 0.2913 & 0.4999 \\
\hline 8 & 8.494 & 31.057 & 0.4239 & 0.1200 & 0.5761 & 1.0000 & 0.3172 & 0.2500 & 0.4361 \\
\hline 9 & 8.974 & 15.041 & 0.1947 & 0.6830 & 0.8053 & 0.3170 & 0.2770 & 0.3796 & 0.5597 \\
\hline 10 & 9.382 & 17.924 & 0.2400 & 0.5381 & 1.0000 & 0.4619 & 0.2500 & 0.3420 & 0.4871 \\
\hline 11 & 9.293 & 16.306 & 0.13000 & 0.6194 & 1.0000 & 0.3806 & 0.2500 & 0.3622 & 0.4901 \\
\hline 12 & 9.057 & 28.636 & 0.0691 & 0.1000 & 0.9309 & 1.0000 & 0.2589 & 0.2500 & 0.4900 \\
\hline 13 & 8.909 & 12.468 & 0.1243 & 0.8078 & 0.8757 & 0.1922 & 0.2666 & 0.4194 & 0.5648 \\
\hline 14 & 8.346 & 16.082 & 0.3346 & 0.6220 & 0.6654 & 0.3780 & 0.3002 & 0.3628 & 0.5815 \\
\hline 15 & 7.955 & 16.199 & 0.4806 & 0.6160 & 0.5194 & 0.3840 & 0.3291 & 0.3613 & 0.4702 \\
\hline 16 & 8.585 & 17.202 & 0.2453 & 0.5644 & 0.7547 & 0.4356 & 0.2850 & 0.3483 & 0.5041 \\
\hline 17 & 7.948 & 8.73 & 0.4832 & 1.0000 & 0.5168 & 0.0000 & 0.3296 & 0.5000 & 0.5454 \\
\hline 18 & 7.317 & 13.936 & 0.7188 & 0.8788 & 0.2812 & 0.1212 & 0.3903 & 0.4459 & 0.5431 \\
\hline 19 & 7.287 & 28.179 & 0.7300 & 0.0000 & 0.2700 & 1.0000 & 0.3937 & 0.2500 & 0.5623 \\
\hline 20 & 9.242 & 15.289 & 0.0320 & 0.7783 & 1.0000 & 0.2217 & 0.2500 & 0.4093 & 0.5050 \\
\hline 21 & 8.621 & 12.69 & 0.1191 & 0.9520 & 0.8809 & 0.0480 & 0.2658 & 0.4771 & 0.5848 \\
\hline 22 & 8.205 & 16.138 & 0.2972 & 0.7216 & 0.7028 & 0.2784 & 0.2936 & 0.3911 & 0.4879 \\
\hline 23 & 8.669 & 14.425 & 0.0985 & 0.8360 & 0.9015 & 0.1640 & 0.2630 & 0.4296 & 0.5046 \\
\hline 24 & 7.805 & 18.489 & 0.4685 & 0.5645 & 0.5315 & 0.4355 & 0.3265 & 0.2500 & 0.5261 \\
\hline 25 & 6.564 & 11.971 & 1.0000 & 1.0000 & 0.0056 & 0.0047 & 0.3421 & 0.3174 & 0.6584 \\
\hline 26 & 6.673 & 17.993 & 1.0000 & 1.0000 & 0.1400 & 0.0062 & 0.4301 & 0.4320 & 0.7520 \\
\hline 27 & 8.899 & 26.936 & 0.3526 & 0.3041 & 0.0000 & 0.0052 & 0.4591 & 0.5210 & 0.6910 \\
\hline
\end{tabular}

TABle 6: Response table for grey relational grade.

\begin{tabular}{lccc}
\hline Level & Pulse on duration $(\mu \mathrm{s})$ & Wire feed $(\mathrm{m} / \mathrm{min})$ & Wire tension $(\mathrm{g})$ \\
\hline 1 & 0.5107 & 0.5200 & 0.5191 \\
2 & 0.5196 & 0.5194 & 0.5739 \\
3 & 0.5921 & 0.5829 & 0.5294 \\
Delta & 0.0815 & 0.0635 & 0.0549 \\
Rank & 1 & 2 & 3 \\
\hline
\end{tabular}

TABLE 7: ANOVA for GRG, with adjusted SS for tests.

\begin{tabular}{lccccr}
\hline Basis & DF & Seq SS & Adj SS & Adj MS & $F$ \\
\hline Pulse on time $(\mu \mathrm{s})$ & 2 & 0.007955 & 0.007955 & 0.003978 & 0.76 \\
Wire feed $(\mathrm{m} / \mathrm{min})$ & 2 & 0.002823 & 0.002823 & 0.001411 & 0.27 \\
Wire tension $(\mathrm{g})$ & 2 & 0.004633 & 0.004633 & 0.002316 & 0.469 \\
Error & 2 & 0.010485 & 0.010485 & 0.005243 & 0.788 \\
Total & 8 & & 0.025896 & \\
\hline
\end{tabular}

Increased pulse length induces additional discharge energy on the surfaces, melting and submerging or partially removing the materials. As a result, as the spark time increases, the MRR developed in the alloys during machining increases slowly. During the spark between the electrodes, the hard Ti-6242 alloy in the compound increases the MRR and removes the particles bound with the matrix. In the Ti-6242 alloy, this results in a faster MRR. The SR of the machining process concentration increases also as pulse length increases, reflecting that more spark is transferred to the composite and the possibility of depression formation, accompanied by scattering and clustering of depressions on the workpiece surface. This is due to the large number of melt dismissals 


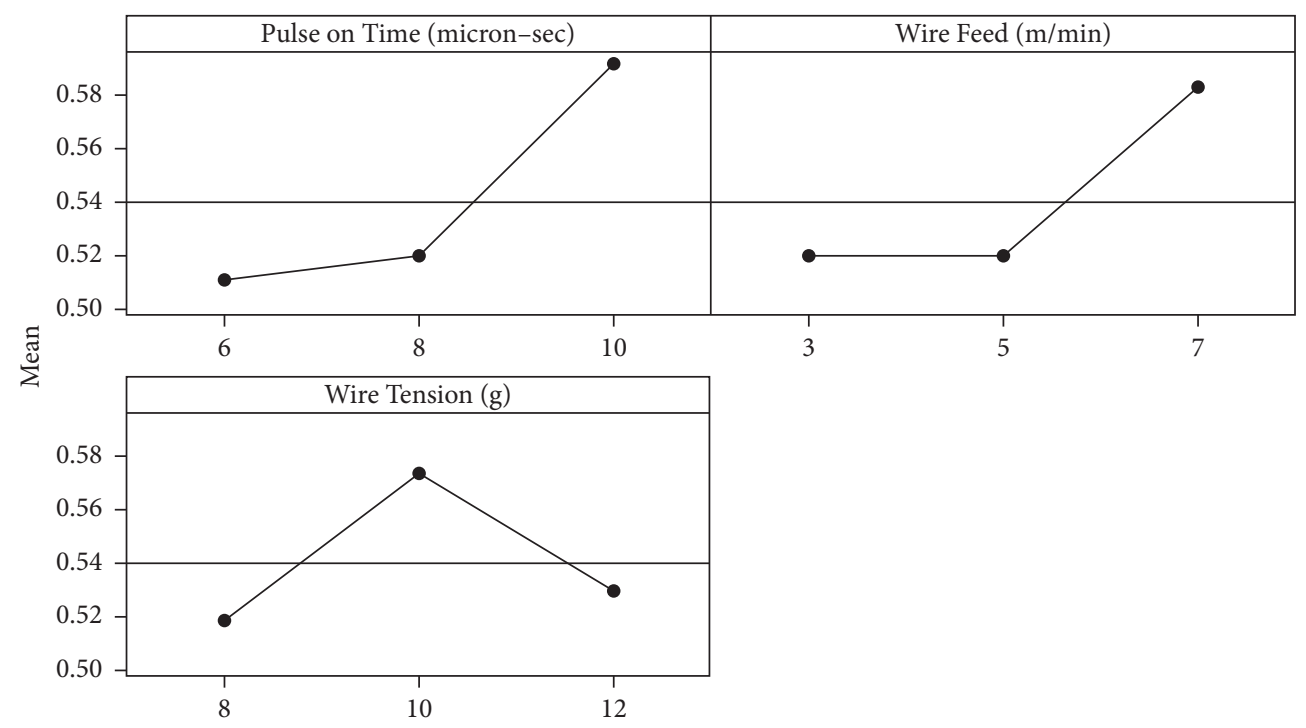

Figure 3: Main effects plot for GRG.

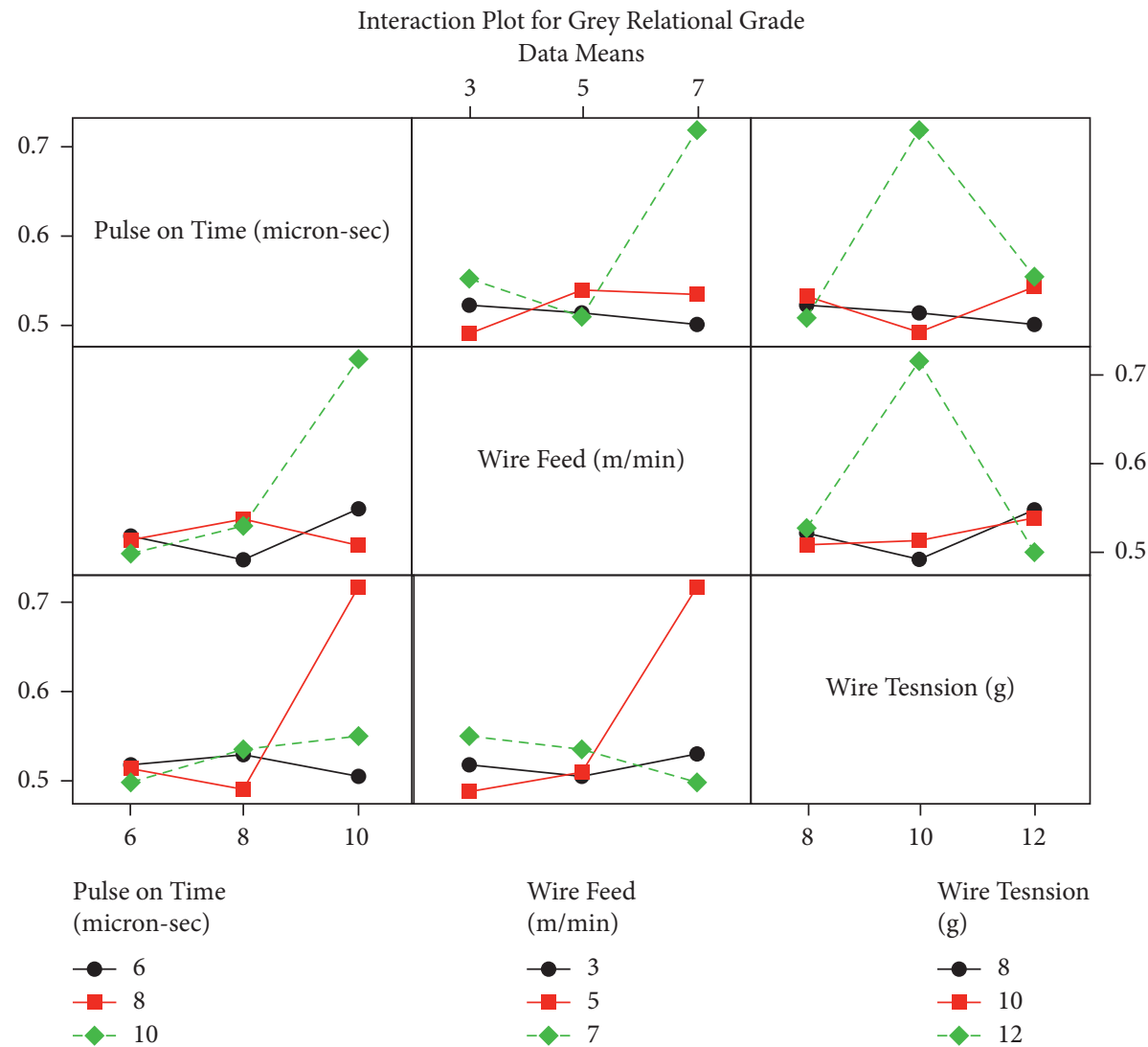

FIgURE 4: Interactions plot for GRG.

that develop on the machining process zone over an extended period of time during the spark, resulting in a poor surface finish. At a constant wire feed, Figures 9(a) and 9 (b) show how surface roughness changes as the spark on time rises.
3.8. Machined Surface Analysis. The machined layer of the titanium alloy material is additionally inspected through scanning electron microscope (SEM) for the surface topography evaluation. Figure 10 shows the machined exterior of the titanium alloy at the improved disorder. The 

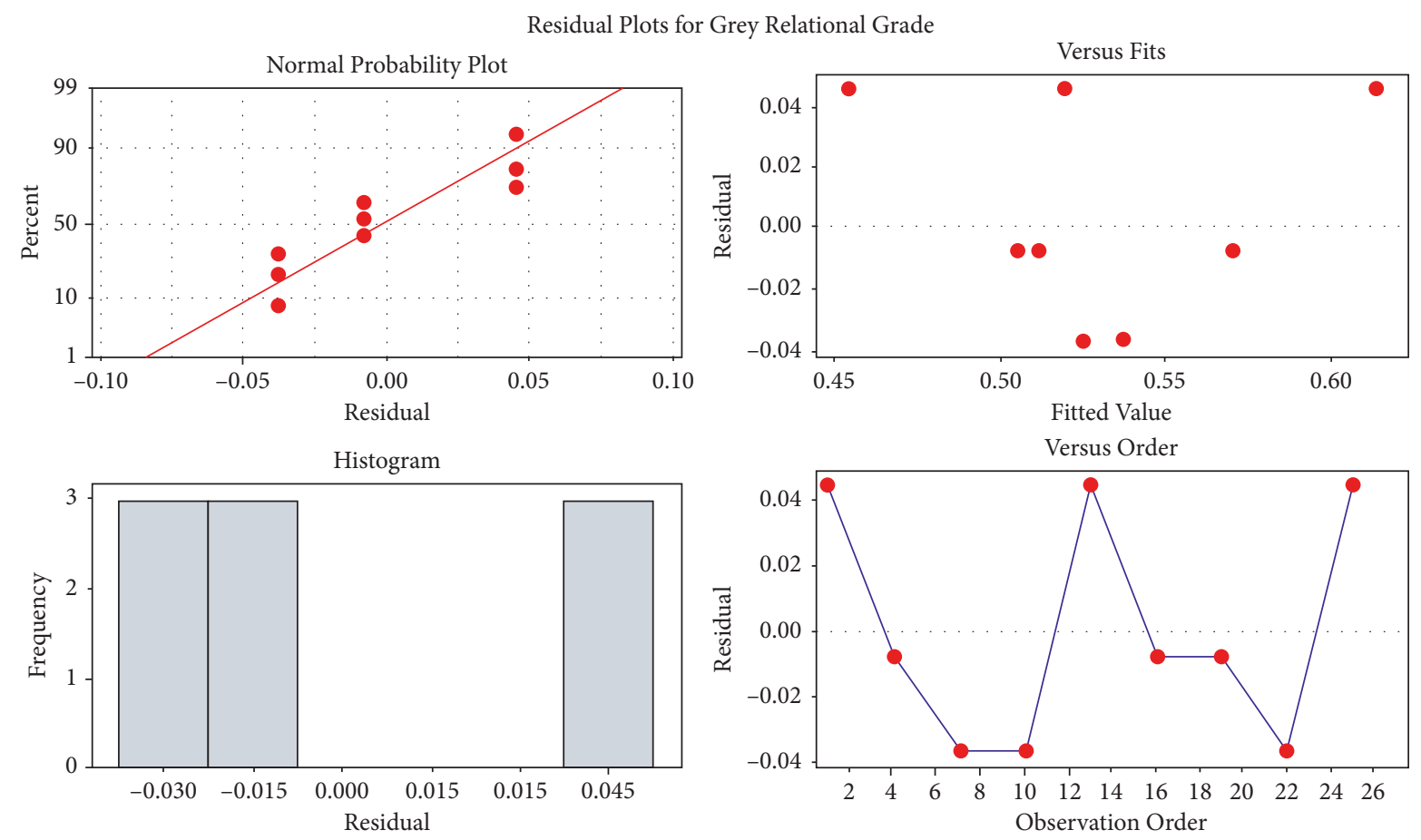

FIgURE 5: Residual plots for grey relational grade.

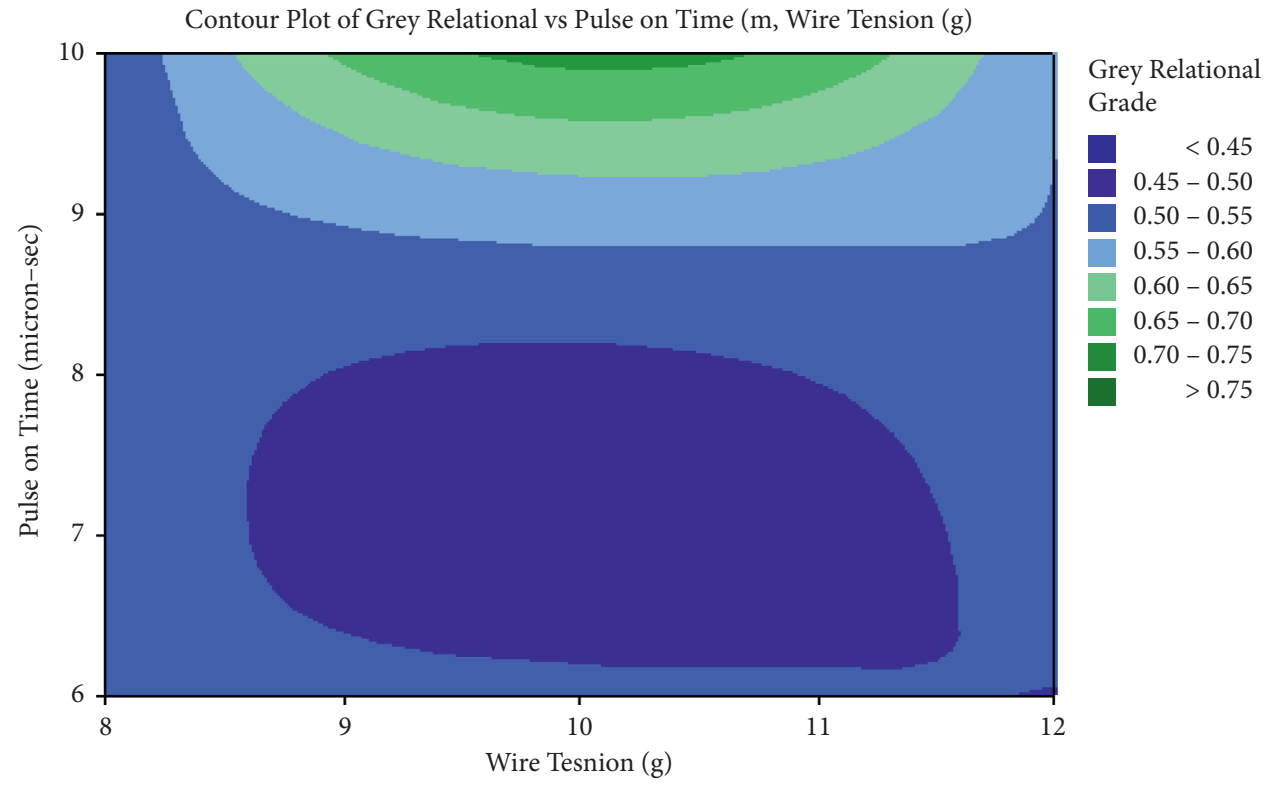

FIgURE 6: Contour plots between pulse on time and GRA.

machined surface with the formation of craters and accumulated craters is visible on the surface. This is owing to the continuous discharge of electrical sparks in a discrete manner which leads to heat the materials and melts it. The molten state of materials is blushed, gone by the dielectric medium passed on to the machined region. However, due to 


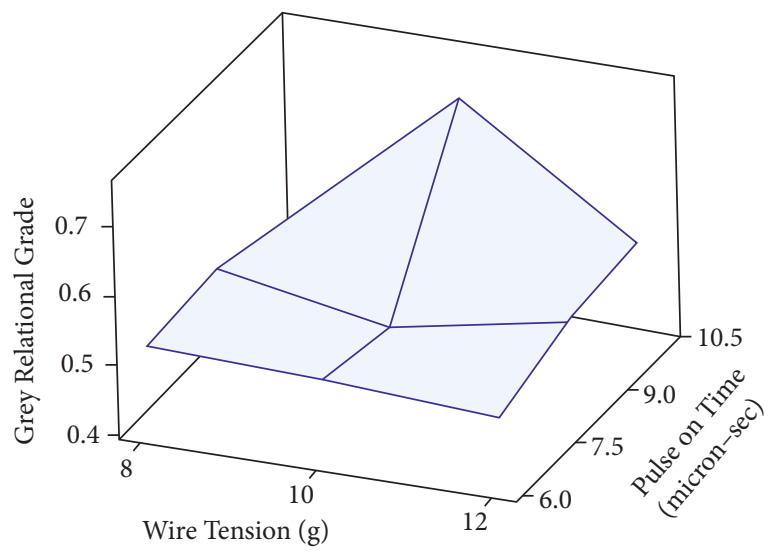

FIGURE 7: Surface plot between pulse on time and GRA.

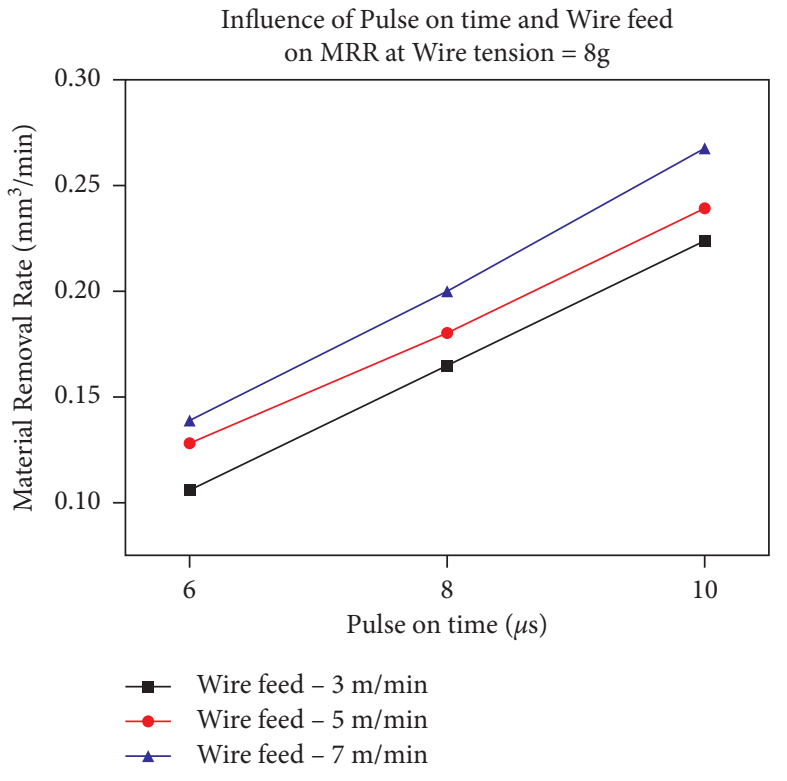

(a)

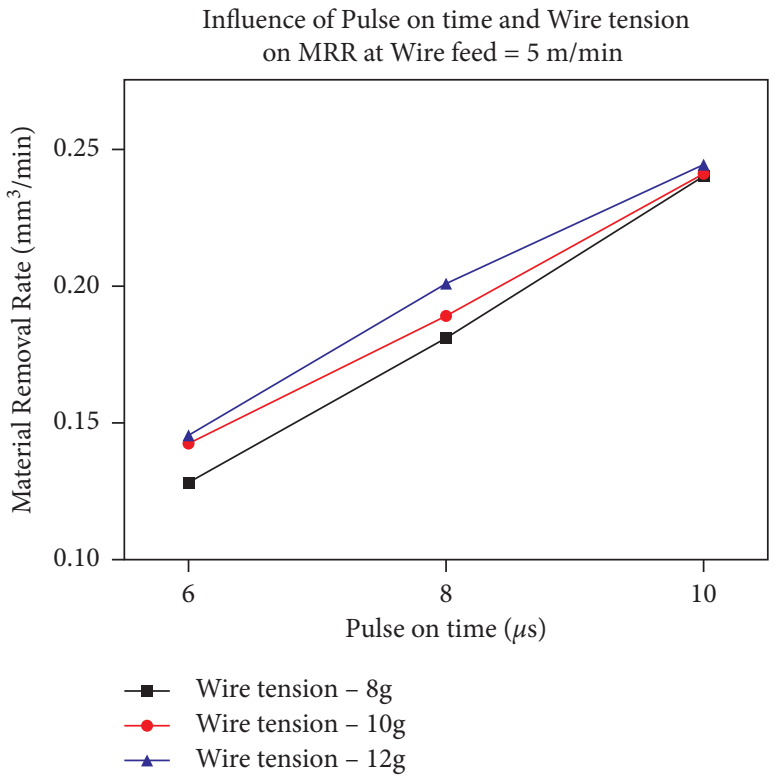

(b)

FIGURE 8: Influence of pulse on time and wire tension on MRR. (a) Influence of pulse on time and wire feed on MMR at wire tension $=8 \mathrm{~g}$. (b) Influence of pulse on time and wire feed on MMR at wire tension $=5 \mathrm{~m} / \mathrm{min}$.

insufficient time being elapsed to flush off the removed material, it is being allowed to solidify on the molted pool itself during the pulse-off time. This forms the layer and crater surface on the machined region.

3.9. Confirmation Test. Following the identification of the most relevant parameters, the final phase is to perform confirmation trials to validate the surface roughness and material removal rate. The A1B1C1 parameter combination is an ideal parameter combination during the WEDM process as determined through grey relational analysis. As a result, the ideal parameter combination's condition A3B1C2 was handled as a confirmation test. The confirmation test yields a surface roughness average and material removal rate identical to those shown in Table 4. 


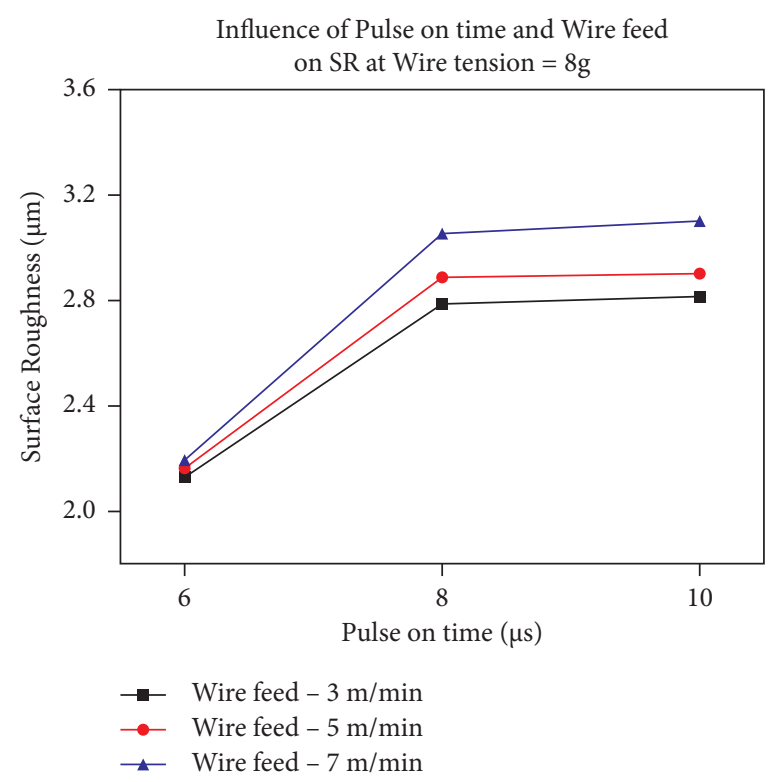

(a)

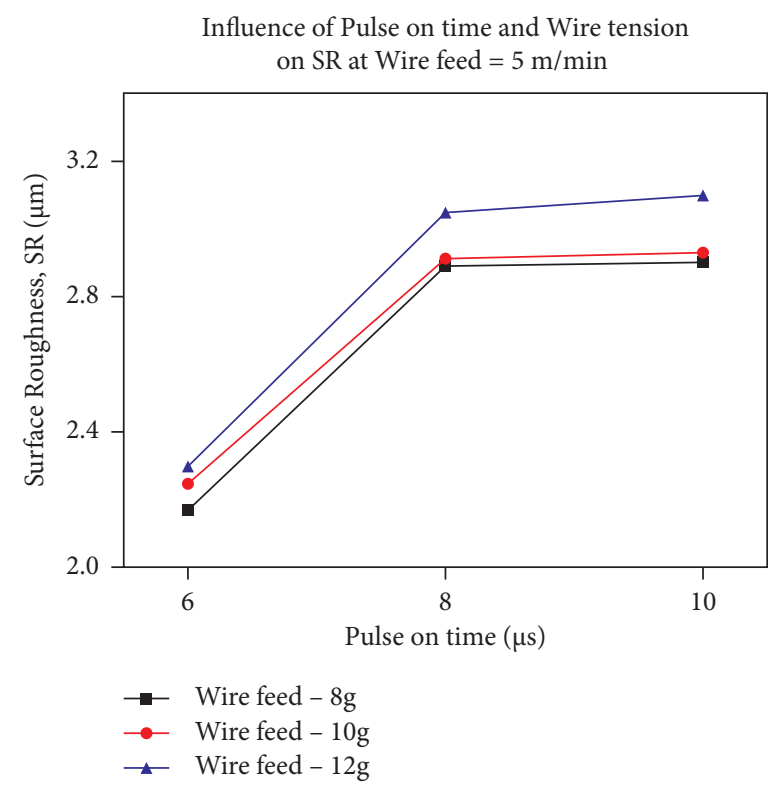

(b)

FIGURE 9: Influence of pulse on time and wire tension on SR. (a) Influence of pulse on time and wire feed on SR at wire tension $=8 \mathrm{~g}$. (b) Influence of pulse on time and wire feed on SR at wire tension $=5 \mathrm{~m} / \mathrm{min}$.
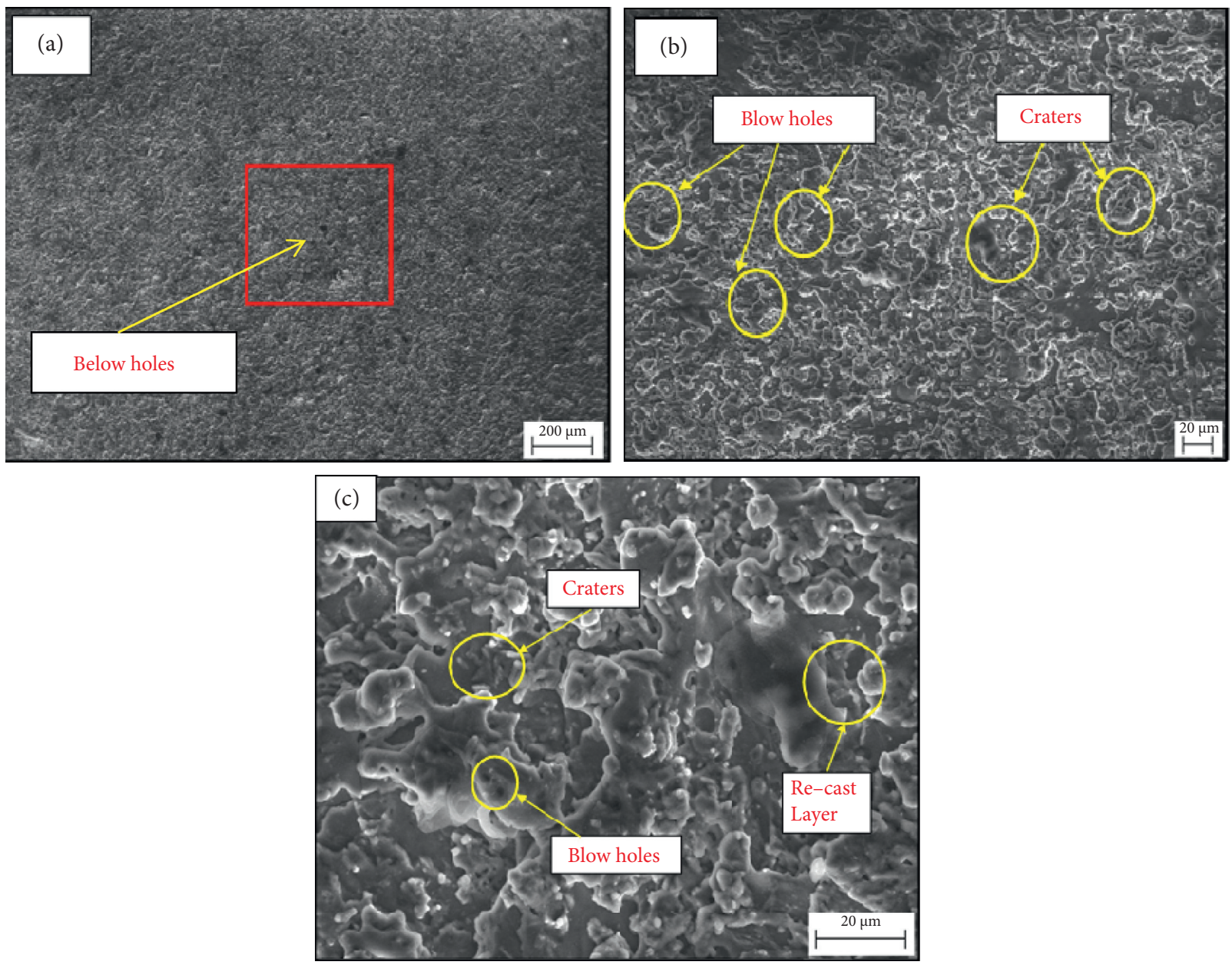

FIGURE 10: SEM images of the WEDM. 


\section{Conclusions}

The experimental investigation on Wire EDM of Ti-6Al$2 \mathrm{Sn}-4 \mathrm{Zr}-2 \mathrm{Mo}$ has been completed by copper wire of $0.25 \mathrm{~mm}$. The following conclusions were drawn.

(i) An effort was made in this investigation to create numerical models with a high-point parametric impact on two assigned advancement responses for MRR and SR.

(ii) The grey-based Taguchi technique was utilized to determine the best factor combination for achieving the highest material removal efficiency and the lowest surface roughness assessment in the specific investigation.

(iii) This strategy is truly solid for beginning multiobjective enhancement issues for consistent quality improvement of the procedure and item. It is realized that the MRR increased and SR decreased, which are useful markers of the effectiveness of the machining procedure.

(iv) Experimental work can be done such that the Gray-Taguchi method can be of perfect use and the legitimate choice of parametric optimization of the wire EDM improvement, when utilizing the numerous presentation attributes such as SR and MRR for machining the Ti-6Al-2Sn-4Zr-2Mo for the issue of some other material.

(v) Specific associations between as far as feasible of execution characteristics were established by the relapse examination technique. Numerical models were created that can be used to evaluate the MRR and SR using leading tests.

(vi) The improved information parameter blends to get the base SR given by Taguchi's improvement strategy are the $6 \mu$ s spark on time, $3 \mathrm{~mm} / \mathrm{min}$ wire feed, and $8 \mathrm{~g}$ wire tension surface roughness improved value of $2.129 \mu \mathrm{m}$, and correspondingly advanced conditions for obtaining the maximum material removal rate are the $10 \mu$ s pulse on time, $7 \mathrm{~mm} / \mathrm{min}$ wire feed, and $12 \mathrm{~g}$ wire voltage material removal rate improved value $0.293 \mathrm{~mm}^{3} / \mathrm{min}$.

(vii) The wire feed, the pulse on duration, and the wire tension are in the order of importance for the controllable parameters to the average surface roughness. The sequence for MRR, on the other hand, is pulse on duration, wire feed, and wire tension.

(viii) The percentage of contribution to the WEDM process, in order, is pulse on duration, wire feed, and wire tension, as determined using ANOVA. When both the surface roughness average and the MRR are minimized at the same time, the Pulse on time becomes the most important controllable factor for the WEDM performance.

\section{Data Availability}

The data used to support the findings of this study are included within the article.

\section{Disclosure}

This study was performed as a part of the employment of the authors.

\section{Conflicts of Interest}

The authors declare that there are no conflicts of interest.

\section{References}

[1] M. Ehsan Asgar and A. K. Singh Singholi, "Parameter study and optimization of WEDM process: a Review," IOP Conference Series: Materials Science and Engineering, vol. 404, no. 1, Article ID 012007, 2018.

[2] A. Perumal, A. Azhagurajan, S. Baskaran, R. Prithivirajan, and P. Narayansamy, "Statistical evaluation and performance analysis of electrical discharge machining (EDM) characteristics of hard Ti-6Al-2Sn-4Zr-2Mo alloy," Materials Research Express, vol. 6, no. 5, Article ID 056552, 2019.

[3] A. Kumar, V. Kumar, and J. Kumar, "Semi-empirical model on MRR and overcut in WEDM process of pure titanium using multi-objective desirability approach," Journal of the Brazilian Society of Mechanical Sciences and Engineering, vol. 37, no. 2, pp. 689-721, 2015.

[4] S. A. V. Baskaran, "Investigations on dry sliding wear behavior of in situ casted AA7075-TiC metal matrix composites by using Taguchi technique," Materials and Design, vol. 60, pp. 184-192, 2014.

[5] M. P. Bhushan, "Multi-objective optimization of process parameters in wire electric discharge machining of Ti-6-2-4-2 alloy," Arabian Journal for Science and Engineering, vol. 39, pp. 1465-1476, 2014.

[6] F. Klocke, D. Welling, A. Klink, D. Veselovac, T. Nöthe, and R. Perez, "Evaluation of advanced wire-EDM capabilities for the manufacture of fir tree slots in Inconel 718," Procedia CIRP, vol. 14, pp. 430-435, 2014.

[7] H. Majumder and K. Maity, "Multi-response optimization of WEDM process parameters using Taguchi based DesirabilityFunction analysis," Materials Science and Engineering: A, vol. 338, Article ID 012004, 2017.

[8] J. T. Huang and Y. S. Liao, "Optimization of machining parameters of Wire-EDM based on Grey relational and statistical analyses," International Journal of Production Research, vol. 41, no. 8, pp. 1707-1720, 2003.

[9] P. K. Saini and M. Verma, "Experimental investigation of wire EDM process parameters on MRR of Ti-6al-4v alloy," International Journal of Innovative Technology and Exploring Engineering, vol. 4, pp. 16-20, 2014.

[10] A. Perumal, A. Azhagurajan, R. Prithivirajan, and S. S. Kumar, "Experimental investigation and optimization of process parameters in $\mathrm{Ti}$ - (6242) alpha-beta alloy using electrical discharge machining," Journal of Inorganic and Organometallic Polymers and Materials, vol. 31, no. 4, pp. 1787-1800, 2021.

[11] S. S. Habib, "Study of the parameters in electrical discharge machining through response surface methodology approach," Applied Mathematical Modelling, vol. 33, no. 12, pp. 43974407, 2009.

[12] A. F. Mansor, M. H. Mohd Radzi, and R. Hussin, "Performance study of WEDMed on Inconel 718 by using response surface methodology," International Review of Mechanical Engineering (IREME), vol. 7, no. N4. 
[13] Y. S. Liao and Y. P. Yu, "Study of specific discharge energy inWEDM and its application," International Journal of Machine Tools and Manufacture, vol. 44, pp. 1373-1380, 2014.

[14] S. S. Mahapatra and A. Patnaik, "Parametric optimization of wire electrical discharge machining (wedm) process using Taguchi method," Journal of the Brazilian Society of Mechanical Sciences and Engineering, vol. 28, no. 4, pp. 422-429, 2006.

[15] V. Muthu Kumar, A. Suresh Babu, R. VenkataSwamy, and M. Rajenthiren, "Optimization of the wire-EDM parameters in machining incolloy -800 super alloy with multiple quality characteristics," International Journal of Science and Technology, vol. 2, no. 6, pp. 1538-1547, 2010.

[16] K. H. Ho, S. T. Newman, S. Rahimifard, and R. D. Allen, "State of the art in wire electrical discharge machining (WEDM)," International Journal of Machine Tools and Manufacture, vol. 44, no. 12-13, pp. 1247-1259, 2004.

[17] E. Ekici, A. R. Motorcu, and A. Kuş, "Evaluation of surface roughness and material removal rate in the wire electrical discharge machining of Al/B4C composites via the Taguchi method," Journal of Composite Materials, vol. 50, no. 18, pp. 2575-2586, 2016.

[18] T. R. Newton, S. N. Melkote, T. R. Watkins, R. M. Trejo, and L. Reister, "Investigation of the effect of process parameters on the formation and characteristics of recast layer in wire-EDM of Inconel 718," Materials Science and Engineering, vol. 513514, pp. 208-215, 2009.

[19] A. Ginting and M. Nouari, "Surface integrity of dry machined titanium alloys," International Journal of Machine Tools and Manufacture, vol. 49, no. 3-4, pp. 325-332, 2009.

[20] M. Nouari and H. Makich, "Experimental investigation on the effect of the material microstructure on tool wear when machining hard titanium alloys: Ti-6Al-4V and Ti-555," International Journal of Refractory Metals and Hard Materials, vol. 41, pp. 259-269, 2013.

[21] I. Bhiradi, L. Raju, and S. S. Hiremath, "Finite element modeling of single spark material removal and heat flux distribution in micro-electro discharge machining process," Lecture Notes in Mechanical Engineering, vol. 35, pp. 297-307, 2019.

[22] S. Sarkar, M. Sekh, S. Mitra, and B. Bhattacharyya, "Modeling and optimization of wire electrical discharge machining of $\gamma$-TiAl in trim cutting operation," Journal of Materials Processing Technology, vol. 205, no. 1-3, pp. 376-387, 2008.

[23] A. Dey, V. R. R. Bandi, and K. M. Pandey, "Wire electrical discharge machining characteristics of AA6061/cenosphere aluminium matrix composites using RSM," Materials Today Proceedings, vol. 5, no. 1, pp. 1278-1285, 2018.

[24] P. J. Ross, Taguchi Techniques for Quality Engineering, Tata McGraw Hill Publishing company limited, New Delhi, India, 2nd edition, 2005.

[25] K. Ishfaq, N. Ahmed, N. A. Mufti, and S. Pervaiz, "Exploring the contribution of unconventional parameters on spark gap formation and its minimization during WEDM of layered composite," International Journal of Advanced Manufacturing Technology, vol. 102, no. 5-8, pp. 1659-1669, 2019.

[26] M. Umar Farooq, M. Pervez Mughal, N. Ahmed, N. Ahmad Mufti, M. A. Al-Ahmari, and Y. He, "On the investigation of surface integrity of Ti6Al4V ELI using Si-mixed electric discharge machining," Materials, vol. 13, 2020.

[27] Z. R. He, S. T. Luo, C. S. Liu, X. H. Jie, and W. Q. Lian, "Hierarchical micro/nano structure surface fabricated by electrical discharge machining for anti-fouling application,"
Journal of Materials Research and Technology, vol. 8, no. 5, pp. 3878-3890, 2019.

[28] A. Kumar, V. Kumar, and J. Kumar, "Multi-response optimization of process parameters based on response surface methodology for pure titanium using WEDM process," International Journal of Advanced Manufacturing Technology, vol. 68, no. 9-12, pp. 2645-2668, 2013.

[29] H. Bisaria and P. Shandilya, "Experimental investigation on wire electric discharge machining (WEDM) of Nimonic C-263 superalloy," Materials and Manufacturing Processes, vol. 34, no. 1, pp. 83-92, 2019.

[30] K. Saptaji, M. A. Gebremariam, and M. A. B. M. Azhari, "Machining of biocompatible materials: a review," International Journal of Advanced Manufacturing Technology, vol. 97, no. 5-8, pp. 2255-2292, 2018.

[31] H. R. Tonday and A. M. Tigga, "An empirical evaluation and optimization of performance parameters of wire electrical discharge machining in cutting of Inconel 718," Measurement, vol. 140, pp. 185-196, 2019.

[32] R. K. Thakur and K. K. Singh, "Experimental investigation and optimization of abrasive water jet machining parameter on multi-walled carbon nanotube doped epoxy/carbon laminate," Measurement, vol. 164, Article ID 108093, 2020.

[33] S. Suresh Kumar, M. Uthayakumar, S. Thirumalai Kumaran et al., "Parametric optimization of wire electrical discharge machining on aluminium based composites through grey relational analysis," Journal of Manufacturing Processes, vol. 20, pp. 33-39, 2015.

[34] P. Kumar, M. Meenu, and V. Kumar, "Optimization of process parameters for WEDM of Inconel 825 using grey relational analysis," Decision Science Letters, vol. 7, pp. 405416, 2018.

[35] V. K. Singh and S. Singh, "Multi-objective optimization using Taguchi based grey relational analysis for wire EDMof Inconel 625," Journal of Material Science and Mechanical Engineering, vol. 2, no. 11, pp. 38-42, 2015.

[36] V. Aggarwal, S. S. Khangura, and R. K. Garg, "Parametric modeling and optimization for wire electrical discharge machining of Inconel 718 using response surface methodology," International Journal of Advanced Manufacturing Technology, vol. 79, no. 1-4, pp. 31-47, 2015.

[37] A. Goswami and J. Kumar, "Investigation of surface integrity, material removal rate and wire wear ratio for WEDM of Nimonic 80A alloy using GRA and Taguchi method," Engineering Science and Technology, an International Journal, vol. 17, no. 4, pp. 173-184, 2014.

[38] V. K. Meena and M. S. Azad, "Grey relational analysis of micro-EDM machining of Ti-6Al-4V alloy," Materials and Manufacturing Processes, vol. 27, no. 9, pp. 973-977, 2012.

[39] A. M. Hatab, F. B. Abudaia, H. Ali Saadawi, and M. E. M. Zorgani, "The use of L9 orthogonal array with grey relational in optimizing of friction welding parameters of $\mathrm{Al}$ $\mathrm{Cu} \mathrm{Bi} \mathrm{Pb}$ alloy," Journal of Materials Science and Engineering, vol. 2, no. 1, pp. 58-65, 2012.

[40] L. B. Abhang and M. Hameedullah, "Determination of optimum parameters for multi-performance characteristics in turning by using grey relational analysis," International Journal of Advanced Manufacturing Technology, 2012.

[41] A. Noorul Haq, P. Marimuthu, and R. Jeyapaul, "Multi response optimization of machining parameters of drilling $\mathrm{Al} /$ $\mathrm{SiC}$ metal matrix composite using grey relational analysis in the Taguchi method," International Journal of Advanced Manufacturing Technology, vol. 37, no. 3, pp. 250-255, 2008. 